This item is the archived peer-reviewed author-version of:

Creating by annotating : the director's notebooks of Jan Fabre and Jan Lauwers

\title{
Reference:
}

De Laet Timmy, Cassiers Edith, van den Dries Luk.- Creating by annotating : the director's notebooks of Jan Fabre and Jan Lauwers

Performance research : a journal of performing arts - ISSN 1352-8165 - 20:6(2015), p. 43-52

Full text (Publishers DOI): http://dx.doi.org/doi:10.1080/13528165.2015.1111050 


\section{Creating by Annotating}

The Director's Notebooks of Jan Fabre and Jan Lauwers

Timmy De Laet, Edith Cassiers and Luk Van den Dries

The eternal is present in the fugitive.

The drawings and the theatre are not an end result.

Everything remains preserved, even if I do not preserve it.

(Jan Fabre 2011: 206)

Drawing is the manuscript of art ...

Drawing is the basis of everything.

(Jan Lauwers 2010: 251)

Annotation is most commonly understood as adding extra layers of information to already existing artworks, manuscripts, performances, poetics, or techniques. This article proposes to reverse this mainly posterior perspective by examining annotation as a 'pre-performance' procedure that is fundamental to processes of artistic creation. To this end, we focus on the notebooks of Jan Fabre and Jan Lauwers, two leading theatre directors who became internationally renowned for their innovative approach to theatrical imagery and dramatic texts. While the oeuvre of both Fabre and Lauwers has received ample attention, the creative processes that characterize their respective artistic practice are a much better kept secret. Their notebooks nevertheless reveal how they both develop various annotative strategies that not only chart the development of their creative thinking -- or thoughtful creating --, but which also demonstrate how annotation permeates the preparatory stages preceding the actual staging of their work. Exposing how both Fabre and Lauwers play with the ambivalent relationship between text and image, writing and performance, script and scene, these working documents show how annotation serves as a structural tool that enables artists to proceed from the realm of imagination to the reality of the stage. 
THE DIDASCALIC IMAGINATION[\{note $\}] 1$

In order to gauge how contemporary theatre directors such as Jan Fabre and Jan Lauwers expand the function of annotation, it is first necessary to consider how annotation is usually figured in theatrical discourse. Véronique Lochert points out that, in theatre, 'the practice of glosses and annotation' is most closely linked to the notion of 'didascalia', which she defines as 'all those paratextual elements [that are] placed in close proximity to the dramatic dialogue' and which include 'the list of characters, the division into acts and scenes, names of speakers and all indications surrounding the lines (2009, 13-14). [\{note\}]2 Patrice Pavis similarly defines so-called 'didascalia' as the 'instructions given by the playwright to the performers ... to guide them in interpreting the dramatic text' $(1998,101)$. Even though in contemporary theatre practice the term 'didascalia' is no longer widely used and often replaced by the more common notion of 'stage directions' (Carlson 1991), didascalia are, from a historical perspective, the theatrical counterpart of what in literary studies are called 'annotations'. It is hardly surprising, then, that the resurging interest of literary scholars in annotation coincides with a heightened attention to didascalia in theatre. This strand of research has manifested itself not so much in Anglophonic but primarily in French theatre studies, as exemplified by the work of scholars such as Thierry Gallèpe (1998), Anne Ubersfeld (1996), Sanda Golopentia (1994), Frédéric Calas (2007) and Matthieu Mével (2013).

Most of these studies meticulously scrutinize the various forms in which didadascalia appear as well as the various perspectives from which they can be approached. Sanda Golopentia, for instance, differentiates between 'meso-', 'macro-' and 'microdidascalias' (1994, 52--54; 101--102), a distinction she later refined in terms of 'framing', 'dynamic' and 'concretizing didascalia' $(1999,16)$. As each of these notions aims to capture a different dimension of the annotations that interlard a dramatic text, they also suggest how the analysis of didascalia too often commits the fault of streamlining the diversity of its object into rather static categorical models. This probably becomes most evident in the difference Golopentia draws between written and oral forms of didascalia. In her opinion, it is primarily the playwright who adds textual 
didascalia to his text, while the director's didascalia mainly concern spoken instructions. It is only 'when a director publishes his mise-en-scène that his didascalias of concretization receive a written form' and these are what Golopentia regards as 'annotations' (17). By defining annotations as written didascalia, Golopentia reinforces the ingrained view that theatre is, first and foremost, about text, without regard of the various other parameters (such as images, movement or space) that are equally important to the coming into being of a given play. This reveals an important bias that not only restricts the scope of these inquiries, but neither does it chime with the various tendencies that inspired Hans-Thies Lehmann to proclaim what he famously called the 'postdramatic theatre' (2005 [1999]).

It is well known that one of the principal characteristics of Lehmann's diagnosis holds that text no longer functions as the primary resource for theatrical creation, insofar as -- from the 1970s onwards -- pioneering theatre practitioners such as Tadeusz Kantor, Robert Wilson or Peter Brook increasingly began to treat body, sound, space and light as equal partners in an attempt to revitalize the tradition of theatre. Whereas this postdramatic shift is now a widely acknowledged phenomenon, current research on the notion of didascalia and theatrical annotation remains curiously indebted to a primarily textual model of theatre, as evident in most of the studies mentioned above. Yet, if one of the hallmarks of postdramatic theatre is the dethroning of the dramatic text, so too do annotative didascalia urge for a renewed understanding that recognizes how words -- whether written or spoken -- are only one amongst manifold means of theatrical expression and artistic creation.

An exhaustive overview of the manner in which theatre directors are currently broadening the forms and functions of annotation would require to discuss, amongst other things, how technological devices -- such as video, collective Dropbox files or social media -- are increasingly becoming a daily instrument that also informs contemporary theatre.[\{note\}]3 But focusing on the technologization of annotation would overlook the arguably more fundamental level at which theatre practitioners are revising the role of annotation by tailoring it to the needs of their distinctive poetics and working methods. Generally speaking, the postdramatic displacement of the theatre text and the concomitant revaluation of the theatrical image is clearly discernible in the annotated 
working documents of directors such as Jan Fabre and Jan Lauwers. Not without coincidence, both directors started their career in the visual arts before turning to theatre. Their theatrical language is therefore primarily geared towards creating compelling scenic images rather than illustrating a text by means of a functional miseen-scène.

Nevertheless, in the midst of the international praise that Fabre and Lauwers received for their theatre of images, it is sometimes forgotten that they are also prolific authors who contribute actively to a contemporary repertoire of theatrical texts. In their artistic practice, the image is not segregated from the text. Verbal and pictorial expression rather stand in each other's service, instigating a mutually reinforcing interaction that ought to bring the best out of both. The oeuvres of Fabre and Lauwers consequently allow to fathom how, in contemporary theatre, annotation functions as an intermedial bridge that always already incorporates both image and text, demonstrating that so-called 'postdramatic theatre' not only goes beyond but also builds further on the tradition of textual drama (see Lehmann 2005 [1999]: 25-27; 30-32).

\section{TEXT IS IMAGE IS WORD IS SPEECH IS PICTURE}

The working documents of Fabre and Lauwers are contemporary versions of what in the German theatre tradition is called das Regiebuch. Historically, das Regiebuch -- or, the director's notebook -- is the materialized outcome of the emancipation of the director, whose function only emerged at the end of the nineteenth century when the privileged status of the dramatic author began to erode. Archival documents such as those of Max Reinhardt or Bertolt Brecht chronicle how directors give shape to their own vision on how a certain play should be staged by adding notes, photographs or small sketches to the text. Yet the fact that most of these annotations are literally situated in the margins of the script, or on an extra page loosely attached to it, quite literally reflects how a director's interpretative stance is still subordinate to the text, which remains the epicentre of theatrical creation. This ratio between text and annotation radically changes from the moment that theatre is no longer primarily about the staging of dramatic texts 
but rather about using the stage for all kinds of theatrical expression, whether verbal, bodily, visual or auditive.

To make this more concrete, let us take a closer look at the interaction between word and image in an exemplary sample of the notes Jan Fabre made while creating The Power of Theatrical Madness (1984), the piece that launched him onto the international theatre scene. Amongst the various documents that chart the creation of this work, the most interesting is probably one of the first drawings that Fabre made quite early during the process. The drawing is dated 3 January 1984 and both the title and image indicate that Hans Christian Andersen's fairy tale 'The Emperor's New Clothes' (1937) is a crucial source of inspiration (fig. 1). While the image shows a naked old man wearing a crown and holding a coat in his right hand, the title -- which reads 'the new clothes of...' -- is placed as a neon lighting above the figure. The text, which seems to fade into the drawing, stresses the ironic contrast between the glamorous heralding of the new emperor and the rather shabby creature supposed to represent it. Most significantly, the right side of the drawing contains annotations that illustrate how Fabre is developing a theatrical poetics that outlines how the piece should be staged. He writes: 'not to be played as a caricature, but as the person of Wim or Roberto'. [\{note\}]4 Such remarks make clear that Fabre is more interested in starting from the singular personality of his performers, rather than wanting them to re-present a given persona. This is corroborated by the drawing on the left side of the document which shows, in profile, a male body with an erected penis that is also projected as a shadow on the background. At that time in the creative process, Fabre was indeed exploring the reality of the body as an alternative to the fictionality of the traditional theatre character. The erection thereby figures as a sign of the real that would bespeak how the body, in its immediate corporeality, cannot lie.

[\{FIGURE 1\}]

[\{FIGURE 2\}]

As a whole, Fabre's working document strikingly illustrates how the image takes centre stage while text is referred to the margins. Instead of drawings elucidating the text, words are now used to clarify the image. This shift comes poignantly to the fore when we put the illustration next to an earlier document that is the first sign of Fabre's 
germinating interest in the theme of the naked emperor (fig. 2). Here we see how Fabre assaults a fragment of the story by crossing out nearly the entire text and by adding a lardy little emperor in the left corner. The word that immediately caught his attention -and now ours -- is 'wondermooi?' (gorgeous?), which Fabre highlighted by placing it in a thick square that also appears to be the top of a hammer -- or is it a sceptre? -- as there is a straight handle attached to it. The question mark that follows the word places doubt on the belief that the emperor's new clothes are astonishingly beautiful, invoking the main plot of the fairy tale that, as Ari De Brabandere points out, is also what Fabre considers 'the essence of theatre: the public wants to be deceived' (1997: 15, our translation).

In contrast to the prominence of text in the second illustration stands the centrality of the figure in the first drawing for The Power of Theatrical Madness. Verbal annotation, however, does remain an important means to give sense to a primarily pictorial imagination. Moreover, in retrospect, the annotative additions reveal a layered stratification that intimate how this drawing, instead of being a momentaneous snapshot, is in fact a continuous work-in-progress to which thoughts, ideas and refinements are added, charting how a given work comes into being. Consider, for instance, how the names of the performers -- 'Wim or Roberto' -- appear most pronouncedly at the middle right of the drawing, while the few lines of notes are more rapidly written down and seem to be added later. This suggests that Fabre was initially sketching out the figure of the emperor and subsequently used the same document to reflect on the actual role he would fulfil in the piece as well as on the required mode of acting. Another annotation that seems to confirm this is located at the right corner of the drawing. Trying to envision the costume of the naked emperor, Fabre first writes 'onzichtbare mantel' (invisible coat), then deletes 'onzichtbare' (invisible) and replaces it by 'geen' (no). These different steps indicate how Fabre is using annotation to arrive at the essence of how he imagines the emperor: no longer undressed and with his coat in the right hand, but naked, as in the original fairy tale.

\section{[\{FIGURE 3\}]}

The paradox of this particular drawing is that, while it clearly stands as an accumulation of notes and sketches, it actually conveys how Fabre is reducing 
theatrical expression to its minimum. Real bodies, real actions, real time - these were the pillars of the artistic credo that Fabre was ardent to put on stage during the 1980s. By invading the representational framework of the theatre with the physical presence of performers, Fabre aimed to undermine the conventions of make-believe and roleplaying that were still governing most of theatrical practice around that time, not the least in Belgium.

Text not only complements the images, but the images also seem to require text in order to become legible and workable. In The Domain of Images (1999), James Elkins writes that 'we hope that the pictures we are interested in will always have enough structure to yield meanings -- to be, in the inevitable metaphor, legible' (57). What compromises this presumed hope, however, is the concomitant desire that pictures are 'pure' or, as Elkins explains, that images are 'unsullied by writing or any verbal equivalents, either in the object or in its interpretation' (55). This is what W.J.T. Mitchell in Picture Theory (1994) calls 'iconophobia', or 'the need to defend "our speech" against "the visual"' (13). Following Elkins and Mitchell, Fabre's use of annotation is a straightforward disruption of essentialist ideas on what pictures are or ought to be, while he also goes against the tacit assumption that theatre is whether about text or image, but never entirely about both at the same time.

\section{CREATIVE COGNITION}

The common ground that Jan Lauwers shares with Jan Fabre is that his roots in the visual arts continue to be the true starting point for all of his artistic activities. 'It is the contemplative centre of my work and my life,' he claims, 'without that medium the other media would not exist' (2010: 451). Invoking Mitchell's dictum that 'all media are mixed media' (2005: 260), Lauwers considers his visual work as closely interwoven with his practice as a theatre director. The time he spends drawing, writing or sculpturing in his own studio clearly spills over into the collective work of theatre making that goes on in the rehearsal space. Yet this creative output of Lauwers hardly ever leaves the intimate seclusion of his personal archive. 'It is my necessary solitude, my only real private time,' he says (2010: 451).[\{note\}]5 In contrast to Fabre's authorized drawings, the notebooks 
of Lauwers are filled with pages that are neither dated nor signed and which only sporadically receive the title of a specific production. Lauwers's notes are, above anything else, private working documents meant for personal use, as a means to pursue and give shape to his thoughts. It is literally a sketchbook, a seemingly random assemblage of scraps and notes that keep a track of his creative process.

With regard to the question of annotation, there is at least one particular notebook of Lauwers that calls for our attention. In the course of his career, Lauwers felt increasingly compelled to start writing his own theatre texts rather than to rely on existing literary material.[\{note\}]6 The piece that is probably best known for this development is his much acclaimed Isabella's Room (2004), but the seeds that came to full fruition here were already present in preceding works, such as Images of Affection (2002). The notebook that documents the creation of this production immediately shows how, compared with the drawings of Jan Fabre, there is a significantly larger amount of text present across these pages. Drafts of scenes, descriptions of a certain atmosphere or situation, enumerations of characters and performers are, next to sketches, among the most salient elements that populate this notebook (fig. 4).

[\{FIGURE 4\}]

Particularly interesting are the lists that outline a range of ideas, each of which is preceded by a dash that literally visualizes how Lauwers is trying to arrange his thoughts and to structure the various possibilities of the imaginative world he aims to bring on stage. On top of this page, for example, we see how Lauwers first makes a temptative outline of the general structure of the piece, drawing a small square around the word 'sprookje' (fairy tale), as if to keep in mind that this is the basic mode of the performance (fig. 5). The next dash is followed by the word 'sniper' and a scrawl that reads as 'destroyal', together with a row of slightly bent arrows. These remind of the light of the bullets that leave a sniper's rifle, anticipating the theme of war that would become a central element in Images of Affection. The full line that follows indicates that Lauwers closed off this thought in order to broach another aspect of his creative search. Now writing in English, he makes a list with 'keywords' that should convey the general quality of the 'dances' in the piece. Below the list Lauwers adds that 'make love' should be the action going on 'center scene', while he subsequently thinks about what music 
should be used ('pop songs / eternal music for 100 / music=praying?'). The last dash is blank and marks how a certain thought was coming up, but not complete enough to find its way to the paper.

\section{[\{FIGURE 5\}]}

Sketchy lists such as these, consisting of fragmentary words and interlarded with punctuation such as dashes, exclamation and question marks are a recurrent feature in the notebooks of several contemporary directors.[\{note\}]7 These too are obviously a distinct form of annotation, albeit that the 'source' being annotated here is neither an existing text or a specific drawing, but rather the director's imagination that, before becoming materialized on the page, unfolds itself within the intimacy of his or her creative mind.

This brings us to another expanded function of annotation. Instead of parasitically drawing on a tangible source, the annotative notes of Lauwers are predominantly aimed at giving a more concrete form and structure to the sometimes contingent nature of artistic creation. In this sense, the seemingly banal act of making lists is indicative of the larger cognitive function that annotation fulfils in creative processes. Frédéric Kaplan points out that making annotations such as 'underlining, resuming or schematizing' are aids that 'facilitate our comprehension of the text ... with the support of the paper', even though the actual 'cognitive effects of reading annotated texts are relatively little studied' (2012, 2, own translation). Despite Kaplan's assertion, however, the last decade has witnessed an expansion of studies committed to scrutinizing the cognitive impact of annotation.[\{note\}]8 In general, this research delivers empirical proof of the arguably common sense intuition that acts of writing, such as making notes or lists, enhances both our intellectual and creative abilities.

Significantly, the emerging attention to the positive influence of annotation on cognition and imagination coincides with a growing awareness that, next to writing, also drawing has similar effects. In Natural-Born Cyborgs (2003), for instance, philosopher and cognitive scientist Andy Clarke describes the function of making sketches for artistic creation in terms that correspond closely to the practice of Jan Lauwers and Jan Fabre. According to Clark, 'the sketchpad is not just a convenience for the artist' but rather a medium that allows for an iterated process of externalizing and re-perceiving [that] 
turns out to be integral to the process of artistic cognition itself' (77). Clark calls this back-and-forth movement between sketching and revising a 'looping process', which in his opinion plays a formative role in modelling the artistic imagination.[\{note\}]9 On Clark's account, this loop primarily takes place as an auto-feedback mechanism between materialized sketches and the creative mind. In the case of the creative processes of Lauwers and Fabre, however, this dynamics also extends beyond the confines of the sketchpad or the notebook, insofar as their drawings feed into the rehearsals, while, conversely, collaborations with performers, dramaturges and set, light or costume designers also find their way back into new drawings.

[\{FIGURE 6\}]

[\{FIGURE 7\}]

In Lauwers's notebook for Images of Affection, this feedback loop is most visible in the repeated appearance of the rabbit mask, which is a topos that also occurs in his visual work. During the piece, various performers wear a large, white helmet that has the shape of a rabbit and which covers the upper side of the head while leaving nose and mouth open (fig. 6). As these masks were fabricated out of the same material used for nuclear warheads, they combined a frivolous pop aesthetics with the severity of warfare.[\{note\}]10 This page taken from Lauwers's sketchbook demonstrates how he is exploring various possibilities: rabbits with five ears or just one; snapped or flapping ears; drooping or upright ears (fig. 7). As some of these drawings are crossed out and replaced by others, the preliminary nature that characterizes the director's notebook is beautifully illustrated here. These sketches are products of trial and error, specimen of an ongoing loop of drawing and thinking that exemplify how the sketching page serves as an arena for experimentation that eventually crystallizes into a blueprint for the actual piece.

Lauwers himself is anything but mystical about this creative stage. 'I am tinkering,' he says, 'and to tinker is extremely important. You have to have the courage to behave as an idiot' (Lauwers 2015: n.p.). Nevertheless, while this particular page testifies to the liberty the artist takes to play around with images, the fact that the rabbit mask eventually became a visual icon of Images of Affection demonstrates that what 
might begin as a free fooling around can end up being a signature symbol for a director's theatrical oeuvre.

\section{ANAMNESIC ANNOTATIONS}

So far we have seen how annotation can serve as an instrument to make idiosyncratic images legible and as a method that enhances creative cognition by means of fragmentary lists or sketchy drawings. While we have elucidated the first function by referring to Jan Fabre and the second one by focusing on Jan Lauwers, it is important to stress that these two expanded functions of annotation can be found in the notebooks of both directors. The most important common ground, however, resides in the overall position these notebooks fulfil in their creative processes and, by extension, in theatrical creation in general. What is striking about the practice of both Fabre and Lauwers is that they consistently return to the artistry of drawing and the materiality of the page in order to conceive their work. Their reliance on the medium of the notebook signals that, even in a digitalized culture in which fleeting data often take precedence over tangibly inscriptive means, a material externalization of the internal imagination is still highly relevant.

The apparent importance of the annotated notebook for a director's artistic practice can be understood as a contemporary offset against Plato's infamous condemnation of writing as a threat to living memory and innate knowledge. In his dialogues Meno (c. 380 BC) and Phaedrus (c. 360 BC), Plato prophesied that the rise of technic or prosthetic memory aids -- what he termed 'hypomnesis' - would result in the gradual decline of so-called 'anamnesis' or the innate epistemic capacities of human being. It is well-known that Jacques Derrida fiercely attacked Plato for construing an antagonistic relationship between hypomnesis and anamnesis and for obscuring the fact that external media have always been essential supplements enabling cognitive processes such as remembering or knowing. More recently, the German media scholar Bernard Stiegler has revived this debate, attempting to restore the materiality of hypomnesis, without reinforcing the Platonic privileging of immaterial anamnesis. In this 
regard, Stiegler's reading of Plato's Meno strikingly resonates without our discussion of director's notebooks and annotation as instruments for artistic creation. [\{note\}]11

Meno contains a passage in which Socrates draws figures in the sand while asking a slave boy to recognize basic geometrical relationships. Stiegler interprets the story as follows:

However mutable it may be, the sand that receives this inscription [of the drawing] can conserve the characteristics of the figure more durably than can the mind of the slave boy. Because the body's mind is essentially fluid, his thoughts are constantly passing away and effacing themselves ... The drawing, as hypomnesic memory, is therefore indispensable to this potential philosopher, the slave boy, and to his passage into action, that is, his anamnesis. It constitutes a crutch for understanding, a space of intuition.

(Stiegler 2010: 74)

Stiegler's evocative description of how the sand functions as an inscriptive surface, necessary for the slave to imagine and gain insight in the geometrical figure drawn by Socrates, is reminiscent of the manner in which Jan Lauwers and Jan Fabre regard the reiterated recourse to the pages of their notebooks. Drawing 'furnishes time for thinking,' says Lauwers, 'it is not about the result then but about the action, the perception, it broadens your mind. If you ever have drawn, you look differently at an image and its construction' (2015: n.p.). Fabre, who describes his drawing practice as a 'dancing with the wrists', similarly claims that, for him, it is a matter of 'drawing while thinking and thinking while drawing', just as much as 'drawing is writing and writing is drawing' (2013: n.p.).

Like Meno's slave, who needs the material drawing in the sand to activate his understanding and intuition, so too Fabre and Lauwers rely on their notebooks to enhance their creative imagination and to facilitate -- in Stiegler's words -- their 'passage into action'.

\section{THE POETICS OF ANNOTATION}


According to media scholar Peter Krapp, 'annotation remains crucial for the documentation of philological or bibliographical accuracy, or for the demonstration of philosophical or pedantic veracity, [but] it is only rarely a poetic model' (2006: 362, our emphasis). Notebooks of contemporary theatre directors such as Jan Fabre and Jan Lauwers fill in the gap that Krapp deplores in traditional practices of annotation. The interplay between text and image, the groping and exploratory character of both drawings and words, the compelling visual quality of the notes -- these are all elements that reflect how annotation leaves behind its predominantly explanatory function and becomes a means for developing a theatrical poetics. While annotative additions are spread out across these pages, they lack the clearly circumscribed source-text that annotation conventionally requires. The only centre seems to be the artist's imagination, 'An artist always starts from a white page,' Lauwers claims, 'the basics of all art is this void' (2015: n.p.).

Writing about the use of sketches and drawings in contemporary dance, Scott deLahunta remarks that 'the page becomes less a static site for symbolic depiction and more of an interactive object' that dancers rely on to interpret or transmit choreographic movements rather than to merely provide a supposedly enduring representation of them (2004: 62). Similarly, Fabre says that 'there is a difference between his working drawings for theatre and the steps the performer takes to make it his or her own flesh and blood' and to become what he calls 'the neuron of the piece' (2013: n.p.). Annotation, in this regard, is not so much an instrument for elucidation than a starting point for genuine creation, whereby not only directors but also performers adopt and appropriate the material according to the specific needs of a given production.

Director's notebooks are tangible documents in which annotative strategies are visualized and become perceptible. As such, they are crucial instruments in artistic creation that also indicate how the reach of annotation stretches further than the confines of the page. The drawings and texts that one encounters here function as an impetus for the work that goes on in the studio and vice versa, constituting a continuous feedback loop that eventually leads to the staged performance. In this sense, annotations become what Craig Dworkin calls 'textual prostheses'. In his opinion, the 'anatomical terminology' suggested by the footnote, for instance, points to a 
'corporealization of the text' that not only 'requires a physical and spatial context', but which also means that 'the reader's body is put into motion: the eye moves, the head tilts, the hands and fingers work the pages, the arms and torso shift as the book is handled and manipulated' (2013: 77). Directors such as Jan Fabre and Jan Lauwers amplify this intrusion of the body into text as they -- literally and figuratively -- draw on the page in order to forge connections between their artistic imagination and embodied performance.

Retrospectively, then, the annotated notebooks help to chart the genesis of a piece by giving a glimpse of its developing poesis. Creating and annotating thereby mutually reinforce each other, testifying to the fact that any process of creation is a matter of trial and error whose contingency reflects, ultimately, what it means to be human.

\section{NOTES}

1. The title of this section is also the name of the joint research project from which the present article derives. 'The Didascalic Imagination' is an interuniversitary initiative, supervised by Luk Van den Dries (University of Antwerp) and Johan Callens (Vrije Universiteit Brussel), and funded by the Research Foundation Flanders (FWO). The project examines the changing role of director's notebooks in contemporary theatre as a means to gain further insight into the various creative processes that inform theatrical production. As such, it aims to contribute to the emerging field of theatre genetics. For more information, see: http://dighum.uantwerpen.be/didascimagination/.

2. All translations from the French are our own, unless indicated otherwise.

3. The practice of Flemish director Luk Perceval, who currently works at the Thalia theatre in Hamburg (Germany), provides a telling example of how video recordings, computer files and social media can be a constitutive part of creative processes in 
theatre. For a discussion of his working methods, see Cassiers and Crombez (forthcoming).

4. The names refer to two performers in the original staging of the piece, Roberto De Jonghe and Wim Vandekeybus.

5. The most notable exception to this is the solo exhibition Restlesness (2007), which was curated by Jérôme Sans and which showed for the first time an impressive collection of visual works that Lauwers created between 1996 and 2006.

6. The works that Lauwers created during the beginning period of Needcompany were often inspired by literary and dramatic texts, including the work of Ernest Hemingway in the 1991 production Invictos as well as several plays of William Shakespeare. Yet he never staged this material in any traditional way, bending it instead to his own theatrical poetics.

7. For a discussion of the appearance of similar lists and the use of punctuation in the notebooks of Romeo Castellucci, see De Laet and Cassiers 2015.

8. Frédéric Kaplan, who is founder of the Digital Humanities Laboratory (DHLAB) in Switzerland, has done interesting interdisciplinary research on annotation, combining cognitive science, literary studies and linguistics. Other noteworthy studies are Wolfe and Neuwirth 2001; Liu 2006; Johnson et al 2010. Most of these investigations focus on annotation as a pedagogical tool to enhance learning processes in educational contexts.

9. In his more recent book Supersizing the Mind (2008), Clark talks about sketching, drawing, and other related activities as 'surrogate situations' which 'allow human reason to be disengaged .... while at the same time providing a concrete arena to deploy perceptuomotor routines of a fundamentally world-engaging kind' (155). 
10. For more on the recurrent motif of the rabbit mask in Images of Affection and Jan Lauwers's work in general, see Van den Dries (2007) and Le Roy (2007).

11. For a more elaborate discussion of Plato's Meno by Stiegler, see his Technics and Time 1: The Fault of Epithemeus (1998: 95--100).

\section{REFERENCES}

Calas, Frédéric, Elouri Romadhane, Saïdd Hamzaoui, and Tijani Salaaoui (eds) (2007)

Le texte didascalique à l'épreuve de la lecture et de la représentation, Pessac Cedex: Presses Universitaires de Bordeaux.

Carlson, Marvin (1991) 'The status of stage directions', Studies in the Literary Imagination 24(2): 37--48.

Cassiers, Edith and Thomas Crombez (forthcoming) 'Inside the adaptation room: The genetic process of "Die Brüder Karamasow" (Perceval/Meister)', Journal of Digital Humanities.

Clark, Andy (2003) Natural-Born Cyborgs: Minds, Technologies, and the Future of Human Intelligence, New York: Oxford University Press.

Clark, Andy (2008) Supersizing the Mind: Embodiment, Action, and Cognitive Extension, New York: Oxford University Press.

De Brabandere, Ari (1997) Kritisch Theaterlexicon: Jan Fabre, Brussels: Vlaams Theater Instituut.

De Laet, Timmy and Edith Cassiers (2015) 'The regenerative ruination of Romeo Castellucci', Performance Research 20(3): 18--28. 
deLahunta, Scott, Wayne McGregor and Alan Blackwell (2004) 'Transactables', Performance Research 9(2): 62--72.

Derrida, Jacques (2004 [1972]) Dissemination, trans. Barbara Johnson, London and New York: Continuum.

Dworkin, Craig (2013) 'Textual prostheses', in No Medium, Cambridge, MA: The MIT Press, pp. 55--83.

Elkins, James (1999) The Domain of Images, New York: Cornell University Press.

Fabre, Jan (2011) Nachtboek 1978-1984, Antwerp: De Bezige Bij.

Fabre, Jan and Miet Martens (2013) Interview by Edith Cassiers, Frederik Le Roy and Luk Van den Dries. Troubleyn/Laboratorium, Antwerp. Unpublished.

Gallèpe, Thierry (1998) Didascalies: Les mots de la mise-en-scène, Paris: L'Harmattan.

Golopentia, Sanda (1994) 'L'économie des didascalies', in Sanda Golopentia and Monique Martinez Thomas (eds) Voir les didascalies, Paris: CRIC-Ophrys, pp. 17--134.

Golopentia, Sanda (1999) 'Jeux didascaliques et espaces mentaux', in Monique Martinez Thomas (ed) Jouer les didascalies: Théâttre contemporain espagnol et français, Toulouse: Presses Universitaires du Mirail, pp. 15--42.

Johnson, Tristan. E., Thomas N. Archibald and Gershon Tenenbaum (2010) 'Individual and team annotation effects on students' reading comprehension, critical thinking, and meta-cognitive skills', Computers in Human Behavior (26)6: 1496--507.

Krapp, Peter (2006) 'Hypertext avant la lettre', in Wendy Hui Kyong Chun and Thomas Keenan (eds) New Media, Old Media: A History and Theory Reader, New York and London: Routledge, pp.359--73. 
Lauwers, Jan (2010) "'Most questions are more interesting than their answers." Jan Lauwers in conversation with Jérôme Sans', Contemporary Theatre Review 20(4): 449-54.

Lauwers, Jan (2015) Interview by Timmy De Laet, Frederik Le Roy, and Luk Van den Dries. Needcompany, Brussels. Unpublished.

Lehmann, Hans-Thies (1999) Postdramatisches Theater, Frankfurt am Main: Verlag der Autoren.

Le Roy, Frederik (2007) 'When pop meets trauma: On Needcompany's Images of Affection', in Christel Stalpaert, Frederik Le Roy, and Sigrid Bousset (eds) No Beauty for Me There Where Human Life is Rare, Academia Press and IT\&FB, pp. 233--46.

Liu, Keming (2006) 'Annotation as an index to critical writing', Urban Education 41(2): 192--207.

Lochert, Véronique (2009) L'écriture du spectacle: les didascalies dans le théâtre européen aux $16 \mathrm{e}$ et $17 \mathrm{e}$ siècles, Genève: Drosz.

Mével, Matthieu (2013) La littérature théâtrale entre le livre et la scène, Montpellier: Entretemps.

Mitchell, W.J.T. (1994) Picture Theory: Essays on Verbal and Visual Representation, Chicago and London: The University of Chicago Press.

Mitchell, W.J.T. (2005) 'There are no visual media', Journal of Visual Culture 4(2): 257-66.

Pavis, Patrice (1998) Dictionary of the Theatre: Terms, Concepts, and Analysis, trans. Christine Shantz, Toronto and Buffalo: University of Toronto Press. 
Stiegler, Bernard (1998) Technics and Time 1: The Fault of Epithemeus, trans. Richard Beardsworth and George Collins, Stanford, California: Stanford University Press.

Stiegler, Bernard (2010) 'Memory', in W.J.T. Mitchell and Mark B.N. Hansen (eds)

Critical Terms for Media Studies, Chicago: The University of Chicago Press, pp. 64--87.

Ubersfeld, Anne (1996) Lire le théâtre, vol. 1, Paris: Belin.

Van den Dries, Luk (2007) 'Rubens never used green: Affective shifts in the work of Jan Lauwers', in Christel Stalpaert, Frederik Le Roy, and Sigrid Bousset (eds) No Beauty for Me There Where Human Life is Rare, Academia Press and IT\&FB, pp. 53--68.

Wolfe, Joanna L. and Neuwirth, Christine M. (2001) 'From the margins to the center: The future of annotation', Journal of Business and Technical Communication 15(3): 333--71.

\section{Captions}

Figure 1. One of Jan Fabre's first drawings for The Power of Theatrical Madness. 1984. Courtesy of the artist.

Figure 2. Fabre assaults the fairy tale of 'The Naked Emperor'. Not dated. Courtesy of the V.R.T. archive (Flemish Radio and Television) and the artist.

Figure 3. The figure of the naked emperor in The Power of Theatrical Madness. 1984. Photo Robert Mapplethorpe.

Figure 4. Description of characters and plot for Images of Affection. Not dated. Courtesy of the artist. 
Figure 5. Notes for Images of Affection. Not dated. Courtesy of the artist.

Figure 6. The iconic rabbit mask as it appeared in Images of Affection. 2002. Photo Maarten Vanden Abeele.

Figure 7. Sketches for the rabbit mask. 2002. Courtesy of the artist. 